\title{
Empirical Analysis of Determinants of Patient Satisfaction: A Case Study of Primary Health Centres
}

\section{Khursheed $\mathrm{H}^{*}$}

Department of Economics, Central University of Jammu, India

\begin{abstract}
A cross sectional study in which information was collected from different stakeholders involved about various dimensions of primary healthcare provided by Primary Health Centres (PHCs) was done to analyze the functioning of the primary health centres of district Kulgam w.r.t the standard guidelines of Indian Public Health Standards (IPHS) 2012. Out of the total staff sanctioned the deficiency was $15 \%$. Out of the total deficiency the deficiency of doctors was $27 \%$. School health which is the foundation of preventive care was neglected by $40 \%$ of the Primary Health Centres. Patients received only $6 \%$ of the $22.5 \%$ medicine supply available in these health centres. The Primary Health Centres focus more on the curative healthcare and ignore preventive and promotive components of primary healthcare.
\end{abstract}

Keywords: Primary health; Curative healthcare; Doctors; IPHS

\section{Introduction}

Primary healthcare is the foundation of total healthcare of any country because it is cost effective and has huge forward linkages with emphasis more on the prevention of the diseases than their curative aspects. Due to inadequate resources for curative health services, the preventive healthcare in developing countries attains more significance. The main components of the preventive healthcare are immunization, nutrition and environmental awareness. Unfortunately, in the developing countries with huge population, prevalence of mass poverty and expanding income inequalities, the component of preventive healthcare is the neglected side of total healthcare.

\section{Review of Literature}

Easy and affordable access to any service lays the foundation for its use. In the rural areas of northern India, only $76.6 \%$ of the surveyed respondents knew about the presence of PHCs in their area out of these only $36.3 \%$ utilized the services of these health centres [1]. Effective intervention and community participation determine the outcomes of any public service. Outreach visits are significantly higher in southern States than in northern States of India; 89\% and 93\% of the surveyed expecting mothers in Tamil Nadu and Karnataka, respectively were visited by a female health worker in the last trimester of their pregnancy, in comparison to $53 \%$ and $61 \%$ expecting mothers from Bihar and West Bengal, respectively [2]. Non availability of one or more elements in the complete package affects the utilization rates as well as the satisfaction of the PHCs. In the eight states of India, 11\% beneficiaries were dissatisfied, $43 \%$ were satisfied while as another $45 \%$ were partly satisfied with the services of the Primary Health Centres. The dissatisfaction was largely because of non-availability of medicines [3].

\section{Primary Healthcare in India}

After gaining the political freedom, there emerged a national commitment to improve the health of people. The first step in this direction was comprehensive healthcare approach given by Bhore Committee in 1946. This Committee laid the foundation for establishment of network of Primary Health Centres (Primary Health Centres) and the Sub Centres (SC) in India. In 1978 a new approach to healthcare came into existence at Alma Ata (USSR), known as "Primary Health Care". It defined primary healthcare as, "essential healthcare made universally accessible to individuals and acceptable to them, through their full participation and at a cost that community could afford". Thus it was differentiated from the concepts like basic health services, easily accessible care and services provided by general practitioners which were treated as being synonymous with primary healthcare. The primary healthcare approach as envisaged in Alma-Ata declaration is based on principles of social equity, national coverage, self- reliance, inter sectoral co-ordination and involvement of people in the planning and implementation of health programs in pursuit of predesigned common health goals.

The importance attached to primary healthcare in India is because of underlying facts. First, it is the recognition of the importance of intersectoral action for development of health. This emerged because economic growth did not "trickle down" to the poor in India, as economists had assumed. Second, India faced the brunt of numerous infectious diseases which could be combated by only an inclusive healthcare. The third underlying idea is that preventive and promotive actions should not be separated from curative action, because for attaining the desired results proper integration of these is important given the level of poverty in India the curative measures need to be properly supplemented by the preventive healthcare. Fourth, the evidence that there are a range of health activities which are relatively cheap and very effective e.g., immunization and health awareness but did not reach to poor people.

\section{Objectives}

- To analyze the determinants of the patient satisfaction from the Primary Health Centres of Kulgam district.

- To analyze the extent to which the Primary Health Centres provide the services as per standard guidelines of Indian Public Health Standards (IPHS) 2012.

*Corresponding author: Khursheed $\mathrm{H}$, Department of Economics, Central University of Jammu, India, Tel: +919070270080; E-mail: khursheedarreh@gmail.com

Received December 15, 2016; Accepted January 27, 2017; Published February 02, 2017

Citation: Khursheed H (2017) Empirical Analysis of Determinants of Patient Satisfaction: A Case Study of Primary Health Centres. J Glob Econ 4: 234. doi: 10.4172/2375-4389.1000234

Copyright: $\odot 2017$ Khursheed H. This is an open-access article distributed under the terms of the Creative Commons Attribution License, which permits unrestricted use, distribution, and reproduction in any medium, provided the original author and source are credited. 


\section{Methodology}

The current study adopted a cross sectional research design. A predesigned interview schedule was used to get information. In this study, multistage purposive sampling technique was used. In the first stage from the fifteen PHCs, a sample of seven PHCs was selected, which is equivalent to the $46 \%$ of the total PHCs of the district. These seven Primary Health Centres were selected for the study based on the Tehsils. In the second stage ten outpatients were selected from each PHC. In the third stage three villages served by each PHC were selected. The criteria for this selection was one village in which $\mathrm{PHC}$ was located, one village in the vicinity of $\mathrm{PHC}$ village and one village farther from the PHC village. From each village one school head and village head was consulted. In this way total of twenty one village heads and twenty one school heads were selected in the sample. The data were collected from the seventy outpatients, seven medical officers, twenty one village heads and twenty one heads of schools. To find out the main determinants of patient satisfaction from these health centres an econometric technique of Logit model was used.

$$
Y_{i}=B_{1}+B_{2} X_{2}+B_{3} X_{3+} B_{4} X_{4}+B_{5} X_{5}+u_{i}
$$

For brevity of expression, this model could be written as:

$$
Y_{i}=B X_{i}+u_{i}
$$

Since our dependent variable (overall satisfaction) is binary. The two values it can take are satisfied coded as 1 or dissatisfied coded as 0 . Let $P_{i}$ be the probability of outcome, then $P_{i}=1$ if patient is satisfied and $P_{i}=0$ if patient is dissatisfied.

For the outcome yielding satisfied option ( i.e., $Y=1$ ):

$$
\begin{aligned}
& \operatorname{Pr}\left(Y_{i}=1\right)=\operatorname{Pr}\left(B X_{i}+u_{i}\right) \geq 0 \\
& =\operatorname{Pr}\left[u_{i} \geq-(B X)\right]
\end{aligned}
$$

Probability of this outcome depends on the probability distribution of $Y_{i}$ which in turn depends on probability distribution of $u_{i}$. (From equation $I$ since $\boldsymbol{B}$ is fixed and the values of $\boldsymbol{X}$ are given, therefore any variation in $Y_{i}$ is caused by the variation in $u_{i}$ ). By assuming the probability distribution of $u_{i}$ as symmetric around its mean value equation II becomes:

$$
\operatorname{Pr}\left(u_{i} \geq-B X\right)=\operatorname{Pr}\left(u_{i} \leq B X\right)
$$

From II \& III we get

$$
P_{i}=\operatorname{Pr}\left(Y_{i}=1\right)=\operatorname{Pr}\left(u_{i} \leq B X\right)
$$

From equation IV it is clear that $P_{i}$ depends on the particular probability distribution of $u_{i}$. For the Logit model it is assumed that $u$ follows the logistic probability distribution. For the current analysis it can be written as:

$$
P_{i=}\left(1 / 1+e^{-z}\right)
$$

$P_{i}=$ probability of satisfaction and $Z_{i}=B X_{i}+u_{i}$

$$
1-P_{i}=\left(1 / 1+e_{i}^{Z}\right)
$$

$1-P_{i}=$ probability of dissatisfaction and $Z_{i}=B X_{i}+u_{i}$

Equation V and VI are the models used to estimate the probabilities of satisfaction and dissatisfaction of the patients respectively, but these models are non-linear in $\boldsymbol{B}$ 's and $\boldsymbol{X}$ 's. To make these models linear in both $\boldsymbol{B}$ 's and $\boldsymbol{X}$ 's the ratio of the two models is taken, by doing so we get:

$$
\frac{P i}{1-P i}=\frac{1+e^{-Z i}}{1+e^{Z i}} e^{Z i}
$$

Equation VII for current study is nothing but the probability of a patient being satisfied against probability of dissatisfaction; this is the odds ratio in favour of satisfaction. By taking the natural logarithm of equation VII, we get:

$$
\ln \frac{P i}{1-P i}=L i=Z_{i}=B X_{i}+u_{i}
$$

Equation VIII is the required Logit model for our analysis to find the significant determinants of patient satisfaction from the PHCs.

The overall satisfaction of patients is the dependent variable and their age, gender, years of schooling, distance from PHC, satisfaction from waiting period; satisfaction about doctors services, satisfaction about availability of medicines, satisfaction about services of paramedics and satisfaction from laboratory services are the potential independent variables.

Almost $50 \%$ of the patients did not need any type of laboratory test. Hence their interaction with the paramedics and laboratory services is limited. Therefore these two variables could not be used to find their impact on overall satisfaction. There was not much difference among patients about their satisfaction with waiting period, so this variable was also dropped from the model. Years of schooling and gender of patients as the determinants of satisfaction had no adequate support of the reviewed literature, so these two were also dropped from the model. The purpose of dropping some variables was to give more importance to the most significant variables in the model. The final model to be estimated after the identification of variables is:

Overall satisfaction $=f$ \{age, distance, satisfaction with doctors services,

satisfaction with availability of medicines

In symbolic terms:

$\mathrm{O} v=B_{1}+B_{2}$ age $+B_{3} d i s t+B_{4} d o c+B_{5} m e d+u_{i}$

Ov=overall satisfaction

$B_{i}(i \rightarrow 1$ to 5$)$ are respective coefficients.

$B_{1}=$ constant

doc=satisfaction with doctors services

dist $=$ distance

med=satisfaction with medicines

The results of the above model are given in Table 1.

\section{Results}

On an average, the Outdoor Patient (OPD) attendance per PHC is 30 patients per day. It shows that in the rural areas significant percentage of people seek treatment from the public health facilities. Still this percentage is below the 40 as recommended by IPHS. Among the patients seeking treatment from PHCs, $46 \%$ came for maternal and child care services. This significant percentage can be attributed to the fact that these health centres have been strongly connected to the National Rural Health Mission (NRHM), which mainly deals with improving the maternal and child health. An important finding of the study is that the major beneficiaries of the services of PHCs are the most vulnerable and illiterate sections of our society.

Each $\mathrm{PHC}$ received $22.5 \%$ of its required medicine supply. This shortage of required medicine has immense forward linkages in the determination of healthcare delivery of these health centres. This shortage of required medicine supply draws a thick line between the people and their usage of services of these health centres. Only $20 \%$ patients were satisfied from the availability of medicine from these health centres. From Table 1 the coefficient of satisfaction from 


\begin{tabular}{|c|c|c|c|c|}
\hline Variable & Coefficient & Std. error & z-Statistic & Prob. \\
\hline C & -7.227038 & 2.455403 & -2.943321 & 0.0032 \\
\hline AGE & 0.190441 & 0.065735 & 2.897112 & 0.0038 \\
\hline DIST & -0.312249 & 0.202498 & -1.541984 & 0.1231 \\
\hline DOC & 4.079695 & 1.168116 & 3.492543 & 0.0005 \\
\hline MED & 4.370953 & 1.369227 & 3.192279 & 0.0014 \\
\hline McFadden R-squared & 0.471896 & \multicolumn{2}{|c|}{ Mean dependent var } & 0.742857 \\
\hline S.D. dependent var & 0.440215 & \multicolumn{2}{|c|}{ S.E. of regression } & 0.323565 \\
\hline Akaike info criterion & 0.744946 & \multicolumn{2}{|c|}{ Sum squared resid } & 6.805117 \\
\hline Schwarz criterion & 0.905553 & \multicolumn{2}{|c|}{ Log likelihood } & -21.07310 \\
\hline Hannan-Quinn criter. & 0.808741 & \multicolumn{2}{|c|}{ Deviance } & 42.14620 \\
\hline Restr. deviance & 79.80660 & \multicolumn{2}{|c|}{ Restr. log likelihood } & -39.90330 \\
\hline LR statistic & 37.66040 & \multicolumn{2}{|c|}{ Avg. log likelihood } & -0.301044 \\
\hline Prob (LR statistic) & 0.000000 & & & \\
\hline Obs with Dep $=0$ & 18 & \multicolumn{2}{|c|}{ Total obs } & 70 \\
\hline Obs with $\mathrm{Dep}=1$ & 52 & & & \\
\hline
\end{tabular}

${ }^{*}$ Full form of variables given in equation.

Table 1: Determinants of patient satisfaction.

availability of medicines is 4.37 . It means that availability of medicines is significant factor in determining the overall satisfaction of patients from the PHCs. The main reason for this is that usually people from lower income groups go to these health centres for treatment. Patients received only $6 \%$ of the available medicine supply, highlighting the fact that there are enough leakages in medicine supplies. These leakages are also confirmed by $20 \%$ of the village heads.

Time given by a doctor to the patient is very powerful factor in determining the faith of people in these health centres. From Table 1 the coefficient of satisfaction from doctor's service is 4.07. As many as $57 \%$ patients were satisfied from the consultation with the doctor. Since the average patient inflow to these health centres is 30 per day, it means that a patient on average gets $12 \mathrm{~min}$ consultation time from the doctor. Given the simple nature of ailments for which people come to these health centres this is relatively enough consultation time.

From Table 1 the coefficient of distance from a PHC is -0.31 but it is insignificant. It means that distance from PHC is not a significant factor in determining the overall satisfaction of patients. The possible reason for this could be the fact that in the study area on an average each PHC has to cover the population of villages within the range of 7 $\mathrm{km}$. This small distance in modern times, particularly in the study area which has the best road connectivity in the region, is an insignificant variable in deciding the satisfaction of patients from PHCs. Table 1 reveals that the coefficient of age is 0.19 . It means that age is a significant factor in determining the overall satisfaction of patients; the positive coefficient shows that elder people are more satisfied than the young ones from the services of PHCs. The possible reason for this is that most of these health centres are established after 2005; before their establishment people had no access to the healthcare system, now PHC is located in their vicinity, so they have an easy access to the well organised healthcare system and hence feel more satisfied. Young people are dissatisfied with these PHCs because they know that there are certain gaps between the theoretical and practical operations of these health centres.
On an average those patients who require laboratory tests got $68 \%$ of these tests done in the concerned PHCs. It means that as far as basic laboratory tests are concerned, PHCs are well equipped with adequate laboratory manpower and medical equipment.

Regarding the aspect of preventive healthcare, these health centres are lagging behind what is expected from them. With respect to the school health $40 \%$ health centres never paid any visit to local schools for health check up. Among the schools were health check up was done on an average $8 \%$ children were identified with having some health problems. In the surveyed schools $86.7 \%$ used tap as a source of drinking water. As per Census 2011 tap water forms $70.6 \%$ of the total drinking water supply in the study area. Out of this $88.38 \%$ tap water comes from untreated sources. This along with the sanitation problems in the study area highlights the negligence of proper coordination between the PHCs, Public Health Engineering (PHE) department, School Heads and Village Heads to ensure preventive healthcare in the study. The $87 \%$ village heads confirmed that no joint sitting was done in the past year, to promote preventive healthcare in the study area. The negligence of the IPHS guidelines in terms of School visits, Joint sittings with different stakeholders and lack of coordination with the PHE department emerges the weakest link in the delivery of primary healthcare by these health centres.

\section{Conclusion}

The primary health centres are gaining more importance in delivering the health services in the rural areas as more people are coming to seek the treatment from these health centres due to increasing level of literacy, health awareness and increasing expenditure of private healthcare. But these health centres face the acute shortage of drugs which hamper the proper functioning of these health centres, particularly the trust of the patients which is influential for utilization of the services of these health centres. These health centres focus more on the curative healthcare and ignore the preventive aspects.

\section{References}

1. Rajpurohit AC, Srivastava AK, Srivastava VK (2013) Utilization of primary health centre services amongst rural population of northern India - some sociodemographic correlates. Indian Journal of Community Health 25: 445-450.

2. Rama VB (1994) Structure and Utilisation of Health Services: An Inter-State Analysis. Social Scientist 22: 98-111.

3. Nayar R (2000) Public Medicare Unhealthy trends. Economic and Political Weekly 35: 2699-2700. 